\title{
Dramatic rise seen in antibiotic use
}

New report provides the most comprehensive picture yet of antibiotic use and resistance worldwide.

\section{Sara Reardon}

17 September 2015

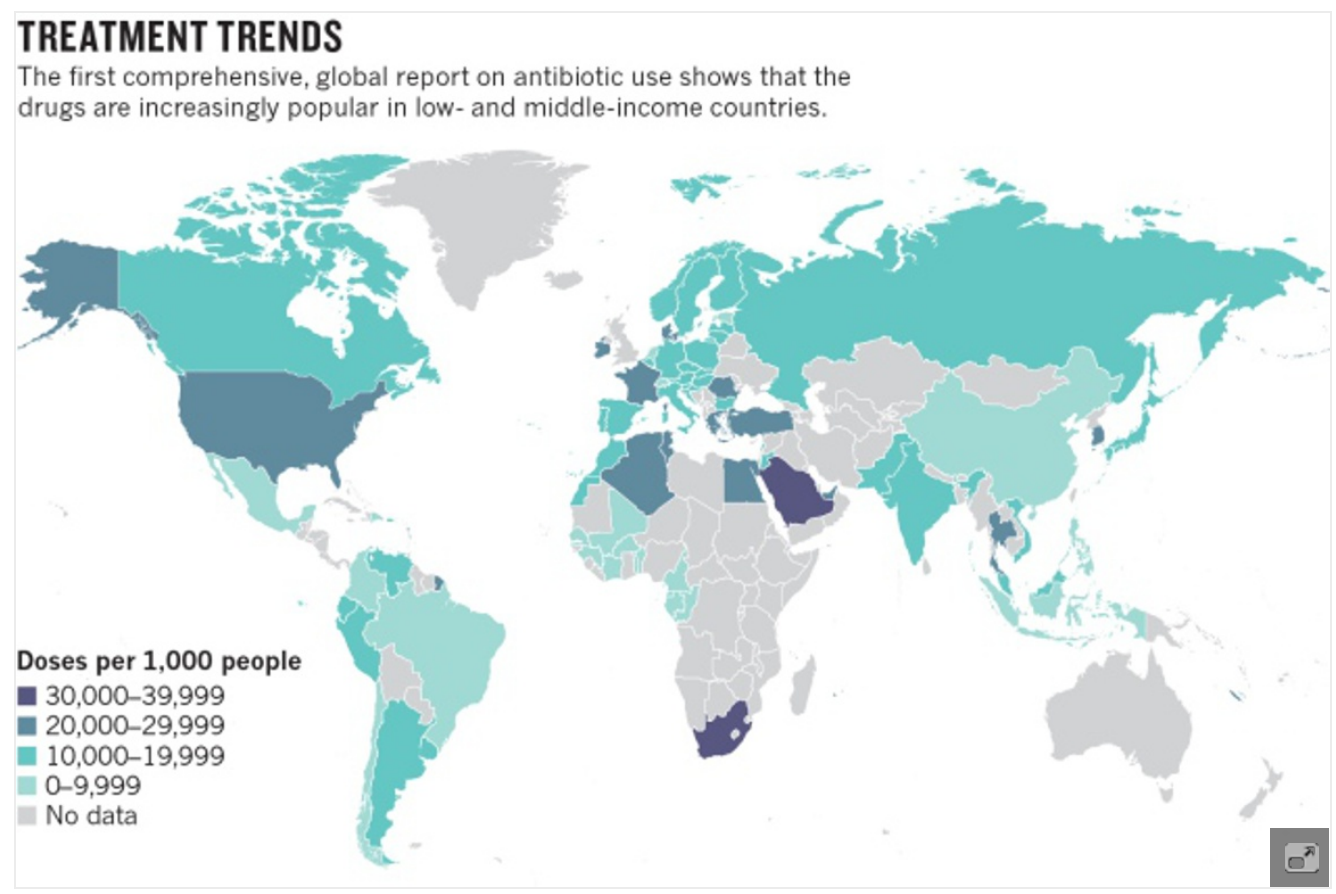

Antibiotic use is growing steadily worldwide, driven mainly by rising demand in low- and middle-income countries, according to a report released on 17 September. The research presents the clearest picture yet of how and where the drugs are used, and the prevalence of different types of antibiotic resistance.

The Center for Disease Dynamics, Economics and Policy (CDDEP), a non-profit group headquartered in Washington DC, based the analysis on data from scientific literature and national and regional surveillance systems. The organization used this to calculate and map the rate of antibiotic resistance for 12 types of bacteria in 39 countries, and trends in antibiotic use in 69 countries over the past 10 years or longer.

Global antibiotic consumption grew by $30 \%$ between 2000 and 2010. This growth is driven mostly by countries such as South Africa and India, where antibiotics are widely available over the counter and sanitation in some areas is poor.

In India, for instance, the number of Klebsiella pneumoniae infections that are resistant to a class of powerful antibiotics called carbapenems doubled from $29 \%$ in 2008 to $57 \%$ in 2014. By contrast, fewer 
The report also found that the use of antibiotics in livestock is growing worldwide. The problem is particularly acute in China, which used about 15,000 tons of antibiotics for this purpose in 2010; the country is projected to double its consumption by 2030 .

\section{Strategies to strive for}

Most high-income countries, by contrast, have begun instituting regulations on antibiotic use, and these are starting to pay off. According to the report, the number of methicillin-resistant Staphylococcus aureus (MRSA) infections, for example, has dropped precipitously in many areas, such as the United Kingdom, over the past eight years.

"I think it's a very thorough and thought-provoking report," says Daniel Sahm, chief scientific officer at International Health Management Associates in Schaumburg, Illinois. Because it is so difficult to gather data from developing countries, he says, the information used in the new analysis might contain holes: an argument for more-aggressive surveillance.

The report lists six steps for preventing antibiotic resistance in countries that do not yet have good policies. Some of those measures, such as improving sanitation, are obvious, whereas policies that restrict antibiotic use in agriculture and hospitals might be more difficult or controversial to implement.

But Timothy Walsh, a medical microbiologist at Cardiff University, UK, says that, although the suggestions offered are worthwhile, international cooperation in setting up a global surveillance network and regulations is necessary to limit the overuse of antibiotics. "We can pour as much money and sentiment and goodwill into the front end of the problem as we want," he says. "But unless we start to have international action and accountability, we're going to just keep on making the same mistakes over and over again."

Nature | doi:10.1038/nature.2015.18383

Tweet Follow@NatureNews Follow @Sara_Reardon

\section{SPRINGER NATURE}

